\title{
INVESTIGATIONS IN MULTIGLASS WINDOW THERMAL QUALITIES
}

\author{
Edmunds Visockis, Raimunds Selegovskis, Uldis Gross, Stanislavs Pleiksnis \\ Latvia University of Agriculture \\ raimunds.selegovskis@1lu.lv, ems@inbox.lv,fkgross@1lu.lv
}

\begin{abstract}
Standard glass package windows for buildings have several drawbacks: the thermal qualities decreases during the service life. The task of the investigation is to define the necessary constructive parameters to develop window package that consists from several glass layers with the air gap between them, the thermal qualities of that remain during lifetime and the thermal conductivity of the window has to be like the thermal conductivity of another building boundary constructions. In contradistinction to the standard window package, where the gap between the glass layers is filled with special gas, in this case the gap is filled with ordinary air. The expenses of such construction can be less than for windows with the standard gas filled double or triple glass package. Moreover, the thermal conductivity of the standard gas filled package increases during lifetime, because, the gas is escaping out of package and the air is filling the gap instead. For high efficiency buildings, losses through windows are very essential. Such solutions allow to level heat losses on all building boundary surfaces. It is very important for buildings with low or zero energy consumption. Using of such windows will promote rational energy utilization. The thermal conductivity of the multiglass package is experimentally determined in the bench for determination of thermal conductivity and calculations of the heat losses through the package with different parameters are carried out.
\end{abstract}

Keywords: heat losses, package windows, multiglass layers, heat saving.

\section{Introduction}

To decrease heat losses through windows, there are more and more progressive window constructions worked out by using multilayer glass packages with different filling medium: argon, krypton and other gasses. The windows become more expensive. But nevertheless, even the most progressive window constructions cannot decrease thermal transmittance to the same level as insulated building walls have.

It is known that approximately $2 / 3$ of all heat losses through the window pane are due to thermal radiation, but the residual $1 / 3$ is due to convection.

Heat is conducted also through the window frame. The rate of conduction (u-value) is governed mostly by the frame material: timber, metal and plastics.

For window panes filled with inert gas like argon or krypton the conductive and convective heat transfer is reduced. Fillings are sometimes used together with so called low-emissivity coatings. Drawbacks of this are more expensive windows and sometimes the filling gas during the service life by diffusion exchanging with ambient air and the windows lose the filling advantages.

In very thin gaps between glasses (less than $1 \mathrm{~cm}$ ), some of the filling gases with low thermal conductance, e.g., krypton, $\mathrm{CClF} 2$, give distinct advantages over the air. As the air gap width increases these gasses show little or no decrease of conductance, but in some cases even increasing of it. Air, argon and $\mathrm{CO}_{2}$ show that the heat flow drops by increasing the width of the air gap [1].

One of the solutions how it is possible to improve the window thermal efficiency is investigated in the publication. Instead of very leek-proof expensive glass packages with special gas filling, it is possible to use multiglass windows with several glass layers in timber frames with air between the glasses.

\section{Materials and methods}

The experimental window is pronounced and dimensions of the experimental window pattern are visible in Fig. 1. It consists of 7 glasses, thickness of the inner glasses is $2 \mathrm{~mm}$ and outside $4 \mathrm{~mm}$. Thickness of the air gap between them is $16 \mathrm{~mm}$. Thereby, by variation of the glass thickness, the weight and production costs of these packages are less. The wooden lath is used as the spacer of the air gap between the glasses, but the glasses are stick to the lath using UV persistent silicone. 

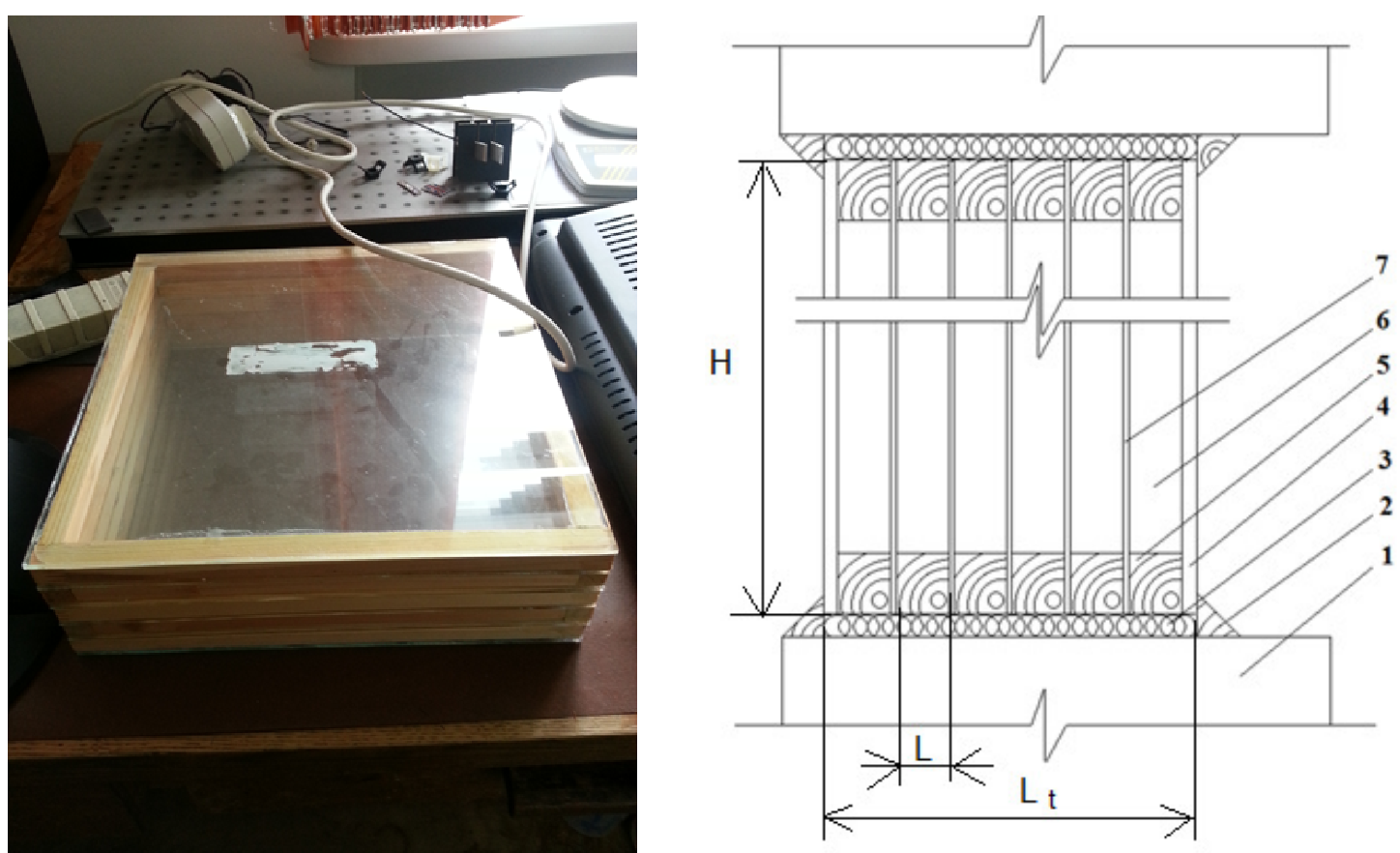

Fig. 1. Experimental multiglass window: 1 - window column; 2 - timber sealing strip; 3 - package sealing; 4 - thick outer glass ( $4 \mathrm{~mm}) ; 5$ - timber spacer; 6 - air gap; 7 - thin inner glass $(2 \mathrm{~mm})$; $H$ - height $(300 \mathrm{~mm}) ; L_{t}$ - total width of window $(96 \mathrm{~mm})$; $L$ - width of each air gap between glasses $(16 \mathrm{~mm})$

The thermal conductivity of the multilayer glass window on variety temperature differences was experimentally determined in horizontal position by the heat flow meter NETZCH HFM 436 Lambda. For thermal conductivity in vertical position, there were made temperature measurings by using 6 temperature sensors ( 3 on cold and 3 on hot side) and 2 heat flow sensors (Fig. 2). The results of the measurements are given in Table 1.

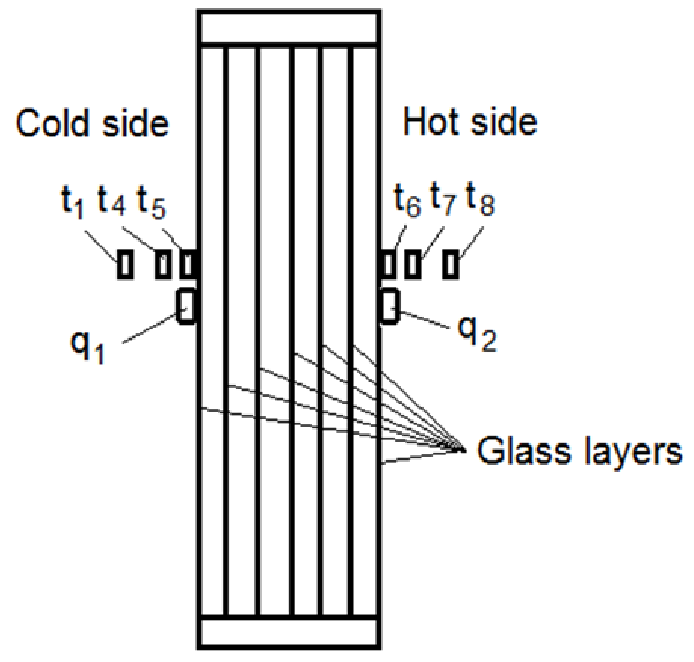

Fig.2. Position of sensors: $\mathrm{t} 1, \mathrm{t} 8$ - sensors of air temperatures; $\mathrm{t} 4, \mathrm{t} 7$ - sensors of air temperatures near outer glass (distance between glass surface and sensor approx. $2 \mathrm{~mm}$ ); t5, t6 - sensors of temperatures on glass outer surfaces; q1, q2 - heat flow meters

\section{Results and discussion}

The amount of the heat flow through air spaces between two glass layers is possible to characterize with the Nusselt number: 


$$
N u=\frac{q L}{\lambda\left(t_{i}-t_{o}\right)},
$$

where $q$-average non-radiative heat flow through the air gap, $\mathrm{W} \cdot \mathrm{m}^{-2}$;

$L-$ width of air layer, m;

$\lambda$ - thermal conductivity of air, $\mathrm{W} \cdot \mathrm{m}^{-1} \cdot \mathrm{K}$;

$t_{i}$ - temperature on warm (indoor) surface, $\mathrm{K}$;

$t_{o}$ - temperature on cool (outdoor) surface, $\mathrm{K}$.

$N u$ is a function of the Rayleigh number $(R a)$, Prandlt number $(P r)$ and ratio A [2]:

$$
R a=\frac{g L^{3} \beta\left(t_{i}-t_{o}\right)}{a v}
$$

where $g$-acceleration of gravity, $\mathrm{m} \cdot \mathrm{s}^{-2}$

$a$ - thermal diffusivity of air at $t_{m}\left(t_{m}=\frac{t_{i}-t_{o}}{2}\right), \mathrm{K}$;

$v$ - kinematic viscosity of air at $t_{m}$;

$\beta$-thermal expansion coefficient of air, $\mathrm{K}^{-1}$.

The Prandlt number is rather similar for different gasses in given conditions and it is not necessary to take it in account during investigation.

Therefore, the thermal qualities of the multiglass window considerably depend on the distance between glasses or the width of the air layer for constant height of the window. For different height ratio A between the height of the window and the width of the air layer it is important:

$$
A=\frac{H}{L},
$$

where $H$-height of window, m;

$L$ - width of air layer or gap between two glasses.

There are two regimes of heat flow between glasses. They depend on the Grashof number and the mentioned ratio A. If the Grashof number is small, there is conduction regime, i.e. heat is transferred by the conduction process. If the Grashof number becomes larger, temperature gradients concentrate in well defined boundary layers near the cold and hot glass surfaces. Now the boundary layer regime sets in. There is also significant linear vertical temperature gradient near the core. Convective heat transfer becomes much more considerable as conduction. Therefore, the thermal conductivity of gas and the kind of gas play less importance.

It is possible to express the convective heat transfer through the air gap [1]:

$$
q_{c}=\frac{\lambda}{L} N u .
$$

The Nusselt number depends on the Grashof number and ratio A:

$$
G r=\frac{g L^{3} \beta\left(t_{i}-t_{o}\right)}{v^{2}} .
$$

As a result it is possible to make the conclusion that by dividing the total air layer to several thin gaps with smaller thickness L using the same height, it will be possible to improve the window heat insulation characteristics.

The best layer width between two glasses is from 14 till $17 \mathrm{~mm}$ to minimize heat losses [2], therefore, the air gap in the experimental window between all glasses was chosen inside this range, i.e. $16 \mathrm{~mm}$.

The temperature measurements were worked out in 6 points (Fig. 2) and when the regime became steady, the heat flow was determined and the heat transfer coefficient $u$ was calculated. 
The obtained summary results of the measurements are given in Table 1.

Heat conductivity measurements of window

\begin{tabular}{|c|c|c|c|c|}
\hline $\begin{array}{l}\text { Position of } \\
\text { window }\end{array}$ & $\begin{array}{c}\text { Temperature } \\
\text { difference } \\
\text { between outer } \\
\text { surfaces } t_{i}-t_{o}, K\end{array}$ & $\begin{array}{c}\text { Heat } \\
\text { conductivity } \lambda_{m}, \\
\mathbf{W} \cdot \mathbf{m}^{-1} \cdot \mathbf{K}^{-1}\end{array}$ & $\begin{array}{l}\text { Thermal } \\
\text { rezistance } R_{t}, \\
\mathbf{m}^{2} \cdot \mathbf{K}^{1} \cdot \mathbf{W}\end{array}$ & $\begin{array}{l}\text { Heat transfer } \\
\text { coefficient } u \text {, } \\
\mathbf{W} \cdot \mathbf{m}^{-2} \cdot \mathbf{K}^{-1}\end{array}$ \\
\hline \multirow{6}{*}{$\begin{array}{l}\text { Vertical } \\
\text { position }\end{array}$} & 10 & 0.0935 & 1.0267 & 0.9740 \\
\hline & 15 & 0.0963 & 0.9966 & 1.0033 \\
\hline & 20 & 0.0983 & 0.9764 & 1.0241 \\
\hline & 25 & 0.0995 & 0.9646 & 1.0367 \\
\hline & 30 & 0.1007 & 0.9533 & 1.0490 \\
\hline & Average: & 0.0976 & 0.9835 & 1.0167 \\
\hline \multirow{6}{*}{$\begin{array}{c}\text { Horizontal } \\
\text { position }\end{array}$} & 10 & 0.0940 & 1.0209 & 0.9795 \\
\hline & 15 & 0.0955 & 1.0001 & 0.9998 \\
\hline & 20 & 0.0978 & 0.9808 & 1.0195 \\
\hline & 25 & 0.0997 & 0.9628 & 1.0386 \\
\hline & 30 & 0.1005 & 0.9549 & 1.0472 \\
\hline & Average: & 0.0975 & 0.9839 & 1.0163 \\
\hline
\end{tabular}

The convection intensity depends on the filling air temperatures. Therefore, experimental investigations were carried out in the correlation between the temperature difference and the intensity of convection that impacts the heat transfer coefficient. The obtained results are represented by diagrams in Fig. 3.

According to the data given in the Latvia building regulations LBN 003-15 "Būvklimatologija" (Building climatology) the average air temperature in central Latvia during the heating season is approximately $0{ }^{\circ} \mathrm{C}$ [3]. The indoor air temperature in premises usually is approximately $22-24^{\circ} \mathrm{C}$. Therefore, in this range of the temperature difference between cold and warm environment the average heat transfer coefficient $\mathrm{u}$ is approximately $1.016 \mathrm{~W} \cdot \mathrm{m}^{-2} \cdot \mathrm{K}^{-1}$.
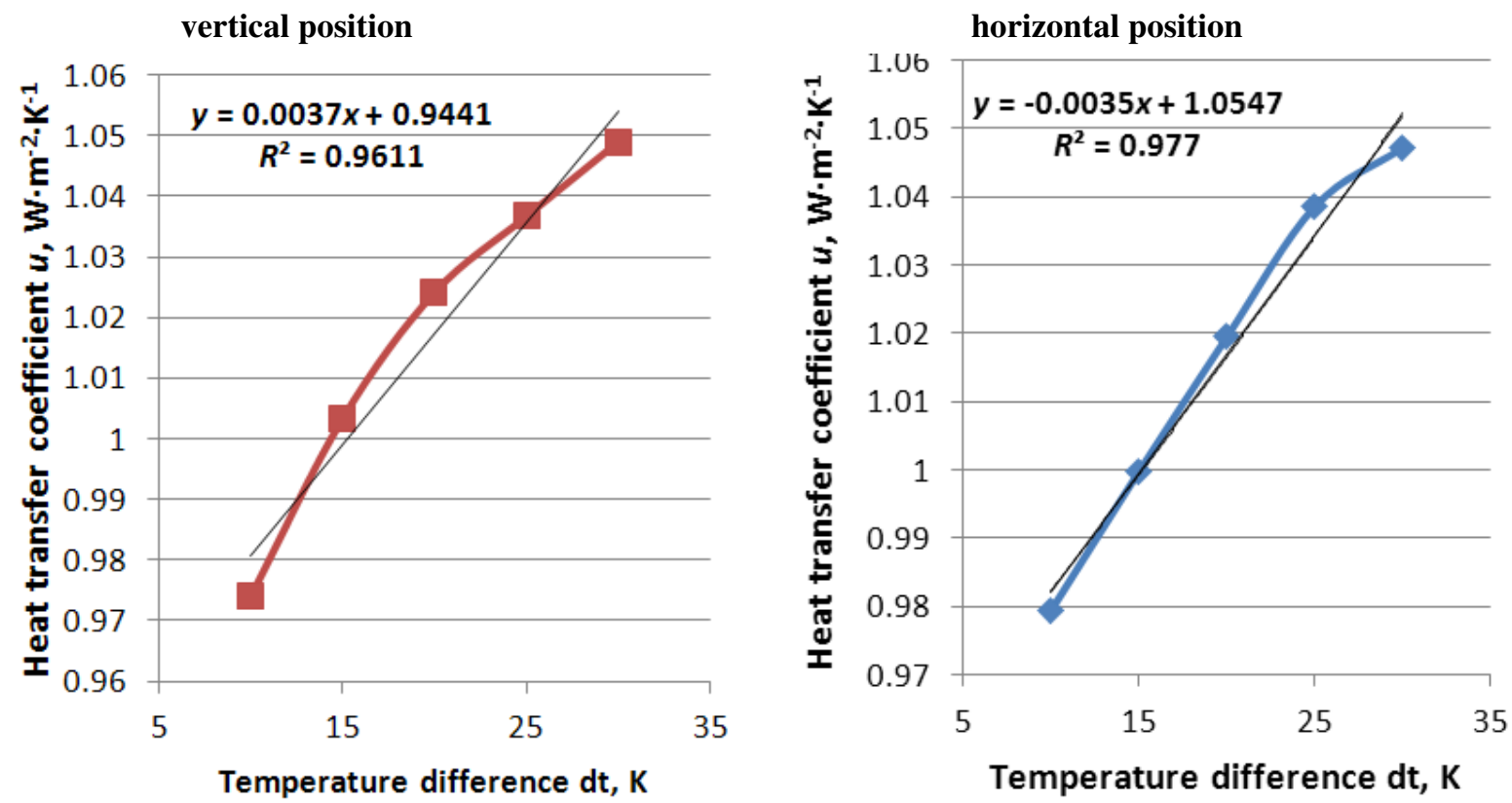

Fig. 3. Experimentally obtained heat transfer coefficient $\mathbf{u}$ for different positions of window

From analysing standard industrially produced double glass package windows of different producers, the $\mathrm{u}$ values of these windows are in the range $1.1-2 \mathrm{~W} \cdot \mathrm{m}^{-2} \cdot \mathrm{K}$. Industrially produced 
windows with higher insulating characteristics with the $\mathrm{u}$ values in range from $0.6-0.8 \mathrm{~W} \cdot \mathrm{m}^{-2} \cdot \mathrm{K}$ are 20-30 \% more expensive [4], because they have different industrially manageable improvements, e.g., reflective coatings of glass, etc. The investigated multilayer glass window has heat transfer characteristics similar to the standard double glass package, but it is cheaper and during the service life there are not possible insulating filling substance leakages, because there is not special substance between glasses, but there is ordinary air.

\section{Conclusions}

1. Average heat transfer coefficient $u$ of the multiglass window with 6 air gaps and the distance between the glasses $16 \mathrm{~mm}$ is $1.016 \mathrm{~W} \cdot \mathrm{m}^{-2} \cdot \mathrm{K}^{-1}$, That is similar with the standard double glass package window.

2. Heat transfer coefficient $u$ depends on temperature, but these changes are rather insignificant in the temperature range for the window working condition temperature range during the heating season. If the temperature difference is changing in the range $20 \mathrm{~K}$, the heat transfer coefficient $\mathrm{u}$ changes only for $0.07 \mathrm{~W} \cdot \mathrm{m}^{-2} \cdot \mathrm{K}^{-1}$ or $0.0035 \mathrm{~K}^{-1}$.

3. The described multilayer window construction is more suitable for producing by craftsmen in home-made conditions. Ordinary carpenter equipment is sufficient to do it and it is not necessary to use special equipment that is needed for producing gas filled window packages but the thermal qualities keep up to the qualities of industrial windows with ordinary gas filling two glass packages.

\section{References}

1. Selkowitz S.E. Thermal Performance of Insulating Window Systems. ASHRAE annual meeting. Michigan. 1979. 19 p. [online] [02.03.2017]. Available at:

http://escholarship.org/uc/item/5g28013t\#page-1

2. Mehran A., Tooraj Y. Numerical analysis of heat transfer in a double glass window. Proceedings of the 7th IASME / WSEAS International Conference on Heat Transfer, Thermal Engineering and Environment. 2009. [online] [06.02.2017]. Available at: http://www.wseas.us/elibrary/conferences/2009/moscow/HTE/HTE37.pdf

3. Ministru kabineta noteikumi Nr. 338. (Regulations No. 338 of the Cabinet of Ministers) Noteikumi par Latvijas būvnormatīvu LBN 003-15 "Būvklimatologija". (Regulations of Latvian Building normative LBN003-15.) 2015. [online] [06.02.2017]. Available at: www.likumi.lv/ta/id/275013-noteikumi-par-latvijas-buvnormativu-lbn-003-15-buvklimatologija

4. Štrausa S. Ziemeḷniece, Brencis R., Vulāns A. Ēkuenergoefektivitāteklimatamaiņasapstākḷıs. (Energoefficiency of buildings in conditions of climate changes) (In Latvian) Jelgava.- 2011. 90 lpp. 